\title{
Continuous local anesthetic infusion through ultrasound-guided rectus sheath catheters
}

\author{
Akemi Shido $\cdot$ Noritaka Imamachi $\cdot$ \\ Katsushi Doi · Shinichi Sakura $\cdot$ Yoji Saito
}

Received: 11 April 2010/Accepted: 12 August 2010/Published online: 28 August 2010

(c) Canadian Anesthesiologists' Society 2010

\section{To the Editor,}

Although epidural analgesia is a gold standard technique for postoperative abdominal analgesia, its use is sometimes limited due to perioperative anticoagulant therapy and undesirable complications such as hypotension. ${ }^{1}$ Rectus sheath (RS) blocks can provide alternative analgesia after midline abdominal surgery. This ultrasound-guided technique has recently gained popularity owing to fewer complications and a higher success rate. ${ }^{2-4}$ Since the duration of the RS block is limited by single injection, it is necessary to develop longer lasting analgesic methods for smooth postoperative recovery. A few attempts using RS catheters have been reported, including continuous administration of a large volume $\left(42 \mathrm{~mL} \cdot \mathrm{hr}^{-1}\right)$ of local anesthetic. ${ }^{3,5}$ However, continuous high-dose local anesthetic infusion may induce local anesthetic systemic toxicity. We report cases in which continuous low-dose local anesthetic infusion through ultrasound-guided RS catheters showed effective postoperative midline abdominal analgesia. Written consent for publication was obtained from each patient.

\section{Case 1}

Despite diagnostic laparoscopy initially being scheduled, a 76-yr-old female weighing $35 \mathrm{~kg}$ underwent gastrointestinal

A. Shido $(\bowtie) \cdot$ N. Imamachi · S. Sakura - Y. Saito

Shimane University Faculty of Medicine, Izumo,

Shimane, Japan

e-mail: a-shido@med.shimane-u.ac.jp

K. Doi

Saitama Medical University, Iruma, Saitama, Japan bypass via upper abdominal midline incision (several $\mathrm{cm}$ in length) under general anesthesia. Postoperatively, bilateral ultrasound-guided RS blocks were performed to reduce unexpected abdominal wall pain. Using a sterile technique, an 18-G Tuohy needle was inserted through the patient's skin at the dermatomal level corresponding to the cephalad end of the wound near the lateral edge of the RS. A linear array probe, 13-6 MHz, S-nerve ${ }^{\circledR}$ (Sonosite Inc., Bothell, WA, USA), was placed longitudinally on the patient's abdominal wall while the needle was advanced using an in-plane technique. After administering $0.25 \%$ ropivacaine $20 \mathrm{~mL}$ in the region between the rectus abdominis muscle and the posterior RS, a 20-G three lateral holes-closed end catheter (Smith Medical, Tokyo, Japan) was inserted through the needle under ultrasound observation (Figure). The same method was applied contralaterally. Intravenous patientcontrolled analgesia (IVPCA) was provided with fentanyl $\left(10 \mu \mathrm{g} \cdot \mathrm{hr}^{-1}\right.$ and $20 \mu \mathrm{g}$ in bolus at request; lockout time, $15 \mathrm{~min}$ ). Three hours postoperatively, the patient's pain intensity assessed by a numerical rating scale (NRS; no pain $=0$, the worst pain $=10$ ) was 0 ; however, severe abdominal pain emerged several hours later. Using disposable infusion pumps (Coopdech Syrinjector, Daiken, Japan), a $10 \mathrm{~mL}$ bolus injection followed by a continuous infusion of $0.125 \%$ ropivacaine $4 \mathrm{~mL} \cdot \mathrm{hr}^{-1}$ were administered through each catheter. Forty-four hours postoperatively, the patient's pain intensity assessed by the NRS was 2 at rest and 4 on coughing.

\section{Case 2}

An 81-yr-old male underwent distal gastrectomy via upper abdominal midline incision (about $15 \mathrm{~cm}$ in length) under general anesthesia. Epidural anesthesia was contraindicated 




FIGURE Ultrasound image of a Tuohy needle and a catheter inserted between the rectus abdominis muscle and the posterior rectus sheath. Tissues appeared disarranged and air-contaminated by the surgical procedures. $\mathrm{SC}=$ subcutaneous tissue; $\mathrm{RA}=$ rectus abdominis muscle; post $\mathrm{RS}=$ posterior rectus sheath; $\mathrm{IP}=$ intraperitoneal space

because of anticoagulant therapy. Postoperatively, bilateral RS blocks were used, followed by a $0.15 \%$ ropivacaine infusion $4 \mathrm{~mL} \cdot \mathrm{hr}^{-1}$ through each catheter. The same IVPCA as in Case 1 was provided. Forty-two hours postoperatively, the patient's pain intensity assessed by the NRS was 0 at rest and 3 on coughing.

\section{Case 3}

A 58-yr-old female who refused to receive epidural anesthesia because of lumbago underwent a partial cystectomy via lower abdominal midline incision (about $15 \mathrm{~cm}$ in length). Postoperative pain was managed in the same manner as in Case 2. Twenty-four hours postoperatively, her pain intensity as assessed by the NRS was 2 at rest and 3 on coughing.
During our observation, no patient received systemic analgesia other than IVPCA (with a few bolus requests in each case).

Although RS block, known as a compartment block, is thought to require a large amount of local anesthetic to provide an analgesic effect, our attempt at continuously infusing a small dose of local anesthetic showed to be effective. We regard the use of ultrasound to ideally place catheters as making it possible to produce sufficient analgesia with a small dosage of local anesthetic. The shortcoming of our method is that catheterization must be performed postoperatively to avoid intraoperative catheter severance. Furthermore, it is cost consuming to use disposable injectors bilaterally. Rectus sheath continuous local anesthetic infusion can be a practical method of postoperative acute pain management. A randomized controlled trial is warranted.

\section{References}

1. Brown DL. Spinal, epidural, and caudal anesthesia. In: Miller RD, editor. Miller's Anesthesia. 7th ed. Philadelphia: Churchill Livingstone, Elsevier Inc; 2009. p. 1611-8.

2. Willschke H, Bosenberg A, Marhofer P, et al. Ultrasonographyguided rectus sheath block in paediatric anaesthesia-a new approach to an old technique. Br J Anaesth 2006; 97: 244-9.

3. Sandeman DJ, Dilley AV. Ultrasound-guided rectus sheath block and catheter placement. ANZ J Surg 2008; 78: 621-3.

4. Dolan J, Lucie P, Geary T, Smith M, Kenny GN. The rectus sheath block: accuracy of local anesthetic placement by trainee anesthesiologists using loss of resistance or ultrasound guidance. Reg Anesth Pain Med 2009; 34: 247-50.

5. Watson D, Farquhar IK, Dennison AR, et al. Postoperative analgesia by infusion of local anaesthetic into the rectus sheath. $\mathrm{Br}$ J Anaesth 1991; 67: 656P. 